\title{
Selection and Energy Saving Analysis of Water Pumps in Center Air Conditioning
}

\author{
Fu Yongzheng ${ }^{1,}$,, Xu Mengyu ${ }^{2, b}$ \\ ${ }^{1}$ Wuhan University of Science and Technology, Wuhan, China \\ ${ }^{2}$ Wuhan University of Science and Technology, Wuhan, China \\ afuyongzheng@163.com ,b13212783067@163.com
}

\begin{abstract}
Keywords: water pump, central air conditioning system, measured date, variable speed regulation, energy saving
\end{abstract}

\begin{abstract}
Analyses the measured data of water pumps in the 10 central air conditioning projects. The results show that the measured flow rate of pump is 19.3 percent higher than that of design flow rate on average, and the measured efficiency of pump is 58.8 percent higher than that of design value on average. The higher flow rate and lower efficiency result from oversized pump head. The rate head is 87.6 percent higher than required head on average in 10 projects, which results in higher actual energy consumption than that of ideal condition. Variables speed regulation of pumps or cuttingimpeller control of pumps will contribute to operation on condition of design flow rate as well as sound energy saving effects.
\end{abstract}

\section{Introduction}

Pump energy consumption is an important aspect of energy consumption of heating and air conditioning systems. And whether the water pump selection appropriate or not has great impact on its energy consumption [1]. The results show: due to the excessive selection, the actual pump efficiency is reduced significantly, the actual flow rate is far greater than the design, thus as to make the energy consumption increased considerably. The author investigates the measured operation data of water pumps (there are all chilled water pumps) in the 10 central air conditioning projects in Wuhan area, in order to understand problems about the overall operation conditions and selection of water pumps in the central air conditioning systems.

\section{The description of several conditions}

In order to describe and analyze conveniently, several conditions will be described firstly. Because the chilled water system in the air conditioning project are usually operating in parallel with two or two or more of the same model pump (Fig.1). The situation that two or more operate in parallel can inference.

In the Fig. 1 ,curve 1 is an characteristic curve of the parallel water pump, curve 2 is a characteristic curve of the system, the intersection $\mathrm{C}$ of two curves is the measured condition, and $\mathrm{C}_{1}$ is a running condition of single pump correspond with $\mathrm{C}$. The flow of condition $\mathrm{C}$ is not only the total flow of system, but also the sum of two pumps.

In the Fig.1, B is the rated conditions of parallel pump, and B1 is the rated conditions of a single pump. A is a theoretical condition, namely a working condition of which design flow is realized exactly in the existing piping system. Assumed that condition A has an average efficiency level of the nameplate condition. For a specific system, when pump working in the condition A, the design flow can be achieved with minimal energy consumption. So referred to herein as the ideal condition.

There is no doubt that coincidence of the three conditions is the best situation, but in fact, the condition B and condition A can't coincide, which caused the separation of C and B and the separation of $\mathrm{C}$ and $\mathrm{A}$. The farther away from the $\mathrm{B}$ and $\mathrm{A}, \mathrm{C}$ and $\mathrm{A}, \mathrm{C}$ and $\mathrm{B}$ also will be farther apart. 


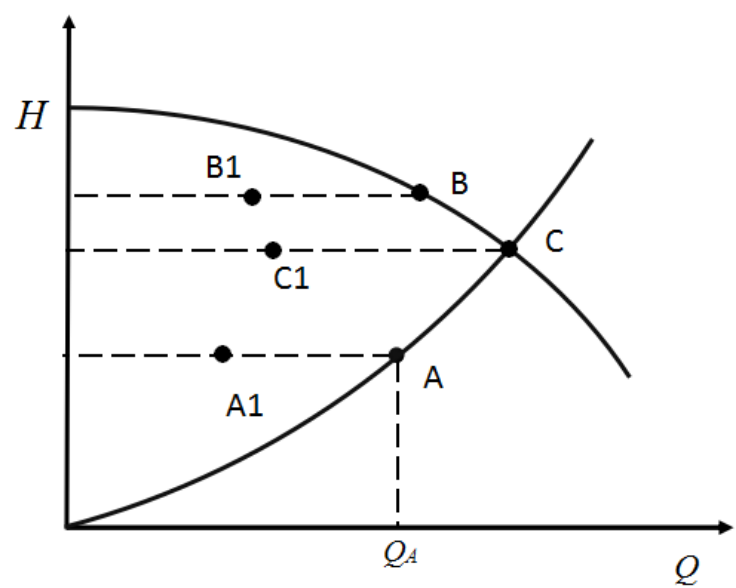

Fig.1 Schematic diagram of several conditions

Condition $\mathrm{A}$ and $\mathrm{C}$ will be determined by the actual measurement and calculation, followed by comparing the A, B, C three kinds of conditions, analysis of the pump selection problems existing in the air conditioning system and the related energy consumption.

\section{The methods of getting working parameters}

Measurement and calculation of condition C. Direct measurement of flow with ultrasonic flow meter under condition $\mathrm{C}$. Using the energy equation to calculate the head on the basis of inlet and outlet pressure gauge reading of water pump. Direct measurement with electric power meter. Efficiency is calculated with the following formula:

$$
\eta_{\mathrm{c}}=\frac{\rho \mathrm{gH}_{\mathrm{C}} \mathrm{Q}_{\mathrm{C}}}{3600 \mathrm{~N}_{\mathrm{C}}}
$$

where $\rho$ is the density of water, $\mathrm{kg} / \mathrm{m}^{3} ; \mathrm{g}$ is the acceleration of free fall, $\mathrm{m} / \mathrm{s} 2 ; \mathrm{H}_{\mathrm{C}}$ is the head of pump, m; $\mathrm{Q}_{\mathrm{C}}$ is the total flow, that is the sum of the flow of parallel pump, $\mathrm{m} 3 / \mathrm{h} ; \mathrm{N}_{\mathrm{C}}$ is shaft power of parallel pump, $\mathrm{kW}$.

Plug $\mathrm{g}=9.807 \mathrm{~m} / \mathrm{s} 2, \rho=1000 \mathrm{~kg} / \mathrm{m} 3$ in the formula, and there is:

$$
\eta_{\mathrm{c}}=\frac{\mathrm{H}_{\mathrm{C}} \mathrm{Q}_{\mathrm{C}}}{367.08 \mathrm{~N}_{\mathrm{C}}}
$$

Determination of condition A. The flow of condition A is the design flow of the system. It can be obtained from the relevant technical data of the project. Characteristic curve 2 of the system is $\mathrm{H}=\mathrm{SQ}^{2}$, then $\mathrm{H}_{\mathrm{C}}=\mathrm{SQ}_{\mathrm{C}}{ }^{2}, \mathrm{H}_{\mathrm{C}}, \mathrm{Q}_{\mathrm{C}}$ are head and flow of measured condition. $\mathrm{H}_{\mathrm{A}}=\left(\mathrm{H}_{\mathrm{C}} / \mathrm{Q}_{\mathrm{C}}{ }^{2}\right) \mathrm{Q}_{\mathrm{A}}{ }^{2}$, in which $\mathrm{Q}_{\mathrm{A}}$ is the flow rate of A condition.

The following assumptions are made on the condition A: sum of the rated flow of each parallel pump is just the design flow of the system, and the nameplate head is just the pressure loss corresponding to the system design flow rate. Then the flow is exactly the rated flow, and the efficiency of the pump is exactly nameplate efficiency in the actual operation. Thus condition A has an average efficiency level of the nameplate condition, which represents the substantially horizontal of pump rated efficiency of air conditioning.

Power of the condition A is calculated by the following formula:

$$
\mathrm{N}_{\mathrm{A}}=\frac{\mathrm{H}_{\mathrm{A}} \mathrm{Q}_{\mathrm{A}}}{367.08 \eta_{\mathrm{A}}}
$$

Acquisition of condition B parameters. The head and efficiency of condition B can be obtained directly from the nameplate. Flow of condition B is the product of a rated flow and the number of parallel pumps. Calculation of power is available by this formula:

$$
\mathrm{N}_{\mathrm{B}}=\frac{\mathrm{H}_{\mathrm{B}} \mathrm{Q}_{\mathrm{B}}}{367.08 \eta_{\mathrm{B}}}
$$




\section{Analysis of the observed and calculated results}

As shown in Table 1using the above method to obtain C, B, A three kinds of working conditions parameters.

Comparison of condition $\mathbf{C}$ and condition B. Compared the difference of efficiency between $\mathrm{C}$ and $\mathrm{B}$ by the above methods. The efficiency of $\mathrm{B}$ condition is $76.6 \%$ on average, and condition $\mathrm{C}$ is $58.8 \%$. The absolute difference between them is $\bar{\eta}_{B}-\bar{\eta}_{C}=17.8 \%$, the relative difference between them is $\left(\bar{\eta}_{B}-\bar{\eta}_{C}\right) / \bar{\eta}_{B}=23.3 \%$. Thus the efficiency of $C$ is much lower than that of $B$.

Table $1 \mathrm{C}, \mathrm{B}, \mathrm{A}$ operating parameters of 10 engineering

\begin{tabular}{c|c|c|c|c|c|c|c|c|c|c|c|c}
\hline \multirow{2}{*}{ Number } & \multicolumn{4}{|c|}{ Condition C } & \multicolumn{4}{c|}{ Condition B } & \multicolumn{4}{c}{ Condition A } \\
\cline { 2 - 13 } & $\mathrm{Q}\left(\mathrm{m}^{3} / \mathrm{h}\right)$ & $\mathrm{H}(\mathrm{m})$ & $\eta(\%)$ & $\mathrm{N}(\mathrm{kW})$ & $\mathrm{Q}\left(\mathrm{m}^{3} / \mathrm{h}\right)$ & $\mathrm{H}(\mathrm{m})$ & $\eta(\%)$ & $\mathrm{N}(\mathrm{kW})$ & $\mathrm{Q}\left(\mathrm{m}^{3} / \mathrm{h}\right)$ & $\mathrm{H}(\mathrm{m})$ & $\eta(\%)$ & $\mathrm{N}(\mathrm{kW})$ \\
\hline 1 & 1323.2 & 27.88 & 58.94 & 174.40 & $600 \times 2$ & 40.5 & 80.79 & $81.93 \times 2$ & 1120 & 19.10 & 76.63 & 76.07 \\
\hline 2 & 701.43 & 22.56 & 51.89 & 83.10 & $310 \times 2$ & 34 & 76.45 & $37.56 \times 2$ & 580 & 15.42 & 76.63 & 31.80 \\
\hline 3 & 362.8 & 18.95 & 44.31 & 42.27 & $177 \times 2$ & 31.2 & 78.52 & $19.16 \times 2$ & 310 & 13.80 & 76.63 & 15.21 \\
\hline 4 & 362.9 & 34.26 & 72.89 & 46.48 & $185 \times 2$ & 32 & 75.6 & $21.34 \times 2$ & 380 & 37.58 & 76.63 & 50.78 \\
\hline 5 & 1307.3 & 22.49 & 59.15 & 135.45 & $600 \times 2$ & 29 & 75.71 & $62.61 \times 2$ & 1114 & 16.33 & 76.63 & 64.69 \\
\hline 6 & 774.6 & 30.03 & 60.41 & 104.92 & $346 \times 2$ & 38 & 72.35 & $49.51 \times 2$ & 630 & 19.87 & 76.63 & 44.51 \\
\hline 7 & 1633.1 & 27.68 & 59.73 & 206.20 & $500 \times 2$ & 34 & 79.31 & $58.39 \times 2$ & 1335 & 18.50 & 76.63 & 87.82 \\
\hline 8 & 1061.57 & 32.27 & 69.54 & 134.22 & $486 \times 2$ & 38.5 & 82.55 & $37.56 \times 2$ & 870 & 21.67 & 76.63 & 67.04 \\
\hline 9 & 386.48 & 29.11 & 54.02 & 56.74 & $182 \times 2$ & 38 & 74.59 & $37.56 \times 2$ & 290 & 16.39 & 76.63 & 16.90 \\
\hline 10 & 1477.47 & 32.77 & 57.03 & 231.33 & $650 \times 2$ & 38 & 70.47 & $37.56 \times 2$ & 1220 & 22.35 & 76.63 & 96.96 \\
\hline
\end{tabular}

Comparison of condition $\mathbf{C}$ and condition A. Table 2 shows that: the relative difference between flow and power of condition $\mathrm{C}$ and condition $\mathrm{A}$.

Table 2 Comparison of condition $\mathrm{C}$ and condition $\mathrm{A}$

\begin{tabular}{c|c|c}
\hline \multirow{2}{*}{ Number } & $\frac{\mathrm{Q}_{\mathrm{C}}-\mathrm{Q}_{\mathrm{A}}}{\mathrm{Q}_{\mathrm{A}}}(\%)$ & $\frac{\mathrm{N}_{\mathrm{C}}-\mathrm{N}_{\mathrm{A}}}{\mathrm{N}_{\mathrm{A}}}(\%)$ \\
\hline 1 & 20.82 & 129.26 \\
\hline 2 & 20.94 & 161.32 \\
\hline 3 & 17.03 & 177.91 \\
\hline 4 & -4.5 & -8.47 \\
\hline 5 & 17.35 & 109.38 \\
\hline 6 & 22.95 & 135.72 \\
\hline 7 & 22.33 & 134.8 \\
\hline 8 & 22.02 & 100.21 \\
\hline 9 & 33.27 & 235.74 \\
\hline 10 & 21.2 & 138.58 \\
\hline Average Value & 19.3 & 131.4 \\
\hline
\end{tabular}

Seen from table 1 and table 2, measured flow of the 10 process is 19.3 percent on average higher than that of the design flow. The work rate of actual measured condition is 2.3 times as much as that of the ideal condition. This difference is due to the head is proportional to the flow squared. The power is proportional to cubic flow rate, which is proportional inversely to efficiency.

Measured flow is $20.8 \%$ higher than the design, and the measured head is $46.0 \%$ higher than the ideal condition. Measured efficiency is $58.9 \%$, which is $17.7 \%$ lower than the condition A. So that the measured power to achieve $174.4 \mathrm{~kW}$.

If the most appropriate pump can be chosen, and pump efficiency is calculated in accordance with the average value of the pump efficiency of 10 projects, then the average energy consumption under design condition is less than half of the current situation. This shows that the energy consumption 
caused by improper selection and pump and system mismatch is amazing. It also shows that pump energy saving of air-conditioning system has a lot of space.

Comparison of condition $B$ and condition A. The degree of deviation from the ideal condition of the condition $\mathrm{C}$ is determined by the degree of the condition $\mathrm{B}$ which deviates from the ideal. Calculating the relative difference of flow and head. As shown in table 3.

Table 3 Comparison of condition $\mathrm{B}$ and condition $\mathrm{A}$

\begin{tabular}{c|c|c}
\hline Number & $\frac{\mathrm{N}_{\mathrm{C}}-\mathrm{N}_{\mathrm{A}}}{\mathrm{N}_{\mathrm{A}}}(\%)$ & $\frac{\mathrm{N}_{\mathrm{C}}-\mathrm{N}_{\mathrm{A}}}{\mathrm{N}_{\mathrm{A}}}(\%)$ \\
\hline 1 & 7.14 & 112.04 \\
\hline 2 & 6.90 & 120.49 \\
\hline 3 & 14.19 & 126.09 \\
\hline 4 & -2.63 & -14.85 \\
\hline 5 & 7.72 & 77.59 \\
\hline 6 & 9.84 & 91.24 \\
\hline 7 & 12.36 & 83.78 \\
\hline 8 & 11.72 & 77.66 \\
\hline 9 & 25.52 & 131.85 \\
\hline 10 & 6.56 & 70.02 \\
\hline Average Value & 9.9 & 87.6 \\
\hline
\end{tabular}

Rated flow are all greater than the design flow except engineering 4. The relative difference of 10 projects between the rated flow and design flow is 9.9 percent on average, head of which is 87.6 percent higher than required head on average in 10 projects.

Author analyzes that there are two reasons for the problem: 1) It will necessarily result in the resistance loss of the system calculation value and the actual value, and also has caused greater deviation between the pump and the actual without careful calculation. It is an important reason for pump selection oversized, flow and energy consumption increased significantly, as well as the efficiency reduced significantly.2) Specifications of HVAC stipulate that flow and head have amount of surplus during the pump selection. For example, there is a specification "Flow and head of pump should have a surplus of $10 \%$ 20\%"; there are many other manuals or the literature have similar requirements[3-8]. If the flow and loss of resistance calculated correctly, pump selection is oversized consequentially in accordance with these requirements.

It is concluded that: 1) That carry out the hydraulic calculation and resistance loss of index circuit is the key to select the pump reasonably. 2) There is no need to take the surplus of flow and head into account in the case of hydraulic calculation has been calculated carefully.

\section{The existing system of technical means to achieve design flow rate}

Working point of the parallel pump is the characteristic curve of the parallel pump and the characteristic curve of the system. Therefore, there are two methods to make the 9 projects achieve the design flow of which the measured flow is greater than the design. One is change the characteristic curve by the throttle adjustment of the valve generally, and the other one is change the characteristic curve of water pump by variables speed regulation and cutting-impeller control of pumps etc.

Throttle regulation. Fig. 2 analyzes characteristic curve of different situations, curve 1 is for the parallel water pump, curve 2 is for the system before the valve throttling, curve 3 is for the system after the valve throttling. A is ideal condition, $\mathrm{B}$ is rated condition, $\mathrm{C}$ is measured condition, $\mathrm{D}$ is throttling condition, the flow of condition $\mathrm{D}$ is exactly the design flow of the system. 


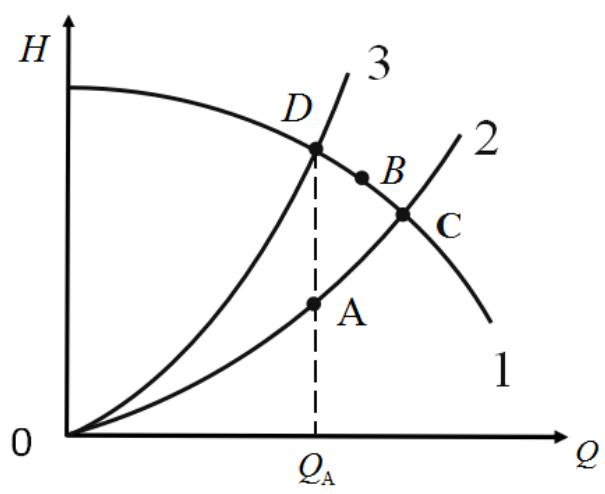

Fig.2 Schematic diagram of throttle control

Table 4 is parameters of throttle condition and comparison of energy consumption between throttle condition and actual condition. Achieving design flow by throttle control contribute to improvement of efficiency and reduction of power. The average efficiency of the pump is raised from $58.8 \%$ to $71.1 \%$, and the work rate is reduced by $8.8 \%$. Condition D happens to be the design flow. Efficiency improved obviously, but the large part of increased head overcome the resistance of the throttle valve causing the less declining of power.

Table 4 Parameters of throttle condition and comparison of energy consumption between it and actual condition

\begin{tabular}{c|c|c|c|c|c}
\hline \multirow{2}{*}{ Number } & \multicolumn{5}{|c}{ Condition $\mathrm{D}$} \\
\cline { 2 - 6 } & $\mathrm{Q}\left(\mathrm{m}^{3} / \mathrm{h}\right)$ & $\mathrm{H}(\mathrm{m})$ & $\mathrm{H}(\%)$ & $\mathrm{N}(\mathrm{kW})$ & $\frac{\mathrm{N}_{\mathrm{C}}-\mathrm{N}_{\mathrm{D}}}{\mathrm{N}_{\mathrm{C}}}(\%)$ \\
\hline 1 & 1120 & 41.50 & 75.63 & 167.46 & 4.00 \\
\hline 2 & 580 & 34.50 & 71.60 & 76.12 & 8.40 \\
\hline 3 & 310 & 31.50 & 69.61 & 38.22 & 9.58 \\
\hline 5 & 1114 & 29.60 & 68.61 & 130.94 & 3.33 \\
\hline 6 & 630 & 39.30 & 70.61 & 95.52 & 8.96 \\
\hline 7 & 1335 & 35.10 & 73.62 & 173.40 & 15.89 \\
\hline 8 & 870 & 39.70 & 77.62 & 121.22 & 9.69 \\
\hline 9 & 290 & 45.20 & 69.61 & 51.30 & 9.59 \\
\hline 10 & 1220 & 39.50 & 62.60 & 209.72 & 9.34 \\
\hline $\begin{array}{c}\text { Average } \\
\text { Value }\end{array}$ & - & - & 71.1 & - & 8.8 \\
\hline
\end{tabular}

Variable speed regulation of pumps. In Fig. 3, C is the actual condition of system, the corresponding pump speed is $n$; the design flow of the system is realized by reducing the speed of two sets of pumps at the same time. The working condition of the parallel pump is changed to $\mathrm{E}$, and the pump speed is $\mathrm{n} 1$ correspondingly. $\mathrm{C}_{1}$ is the operating condition of a single pump correspond to $\mathrm{C}$, and $\mathrm{E} 1$ is the operating condition of a single pump correspond to $\mathrm{E}$.

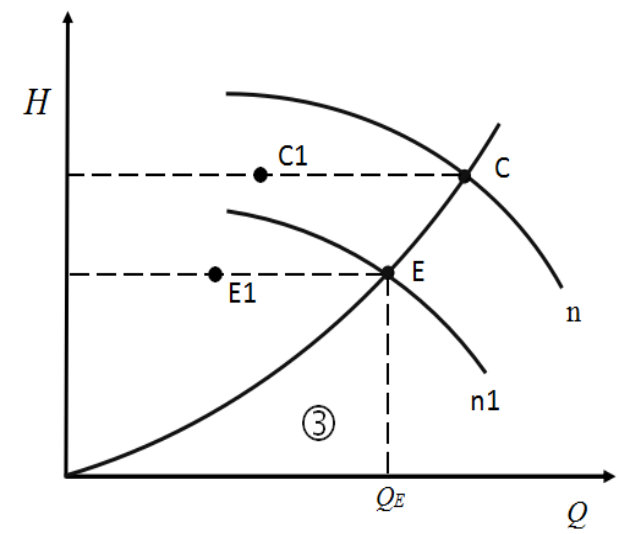

Fig.3 Schematic diagram of variable speed regulation of pumps 
Based on the analysis of the literature [9], when multiple pumps shifting at the same time, the characteristic parameters of the no back pressure system, also meet the proportionality law. Namely:

$$
\frac{\mathrm{Q}_{\mathrm{E}}}{\mathrm{Q}_{\mathrm{C}}}=\frac{\mathrm{n}_{1}}{\mathrm{n}}=\left(\frac{\mathrm{H}_{\mathrm{E}}}{\mathrm{H}_{\mathrm{C}}}\right)^{\frac{1}{2}}=\left(\frac{\mathrm{N}_{\mathrm{E}}}{\mathrm{N}_{\mathrm{C}}}\right)^{\frac{1}{3}}
$$

Where $\mathrm{Q}_{\mathrm{E}}, \mathrm{H}_{\mathrm{E}}, \mathrm{N}_{\mathrm{E}}$ are flow, head and shaft power of parallel pump after changing the speed of the pump.

The shaft power of condition $\mathrm{A}$ as well as the relative difference between condition $\mathrm{A}$ and condition B can be calculated. As shown in Table 5.

Table 5 results of variable speed regulation of pump

\begin{tabular}{c|c|c|c}
\hline \multirow{2}{*}{ Number } & $\mathrm{N}_{\mathrm{E}}(\mathrm{kW})$ & $\mathrm{N}_{\mathrm{C}}(\mathrm{kW})$ & $\frac{\mathrm{N}_{\mathrm{C}}-\mathrm{N}_{\mathrm{E}}}{\mathrm{N}_{\mathrm{C}}}(\%)$ \\
\hline 1 & 98.88 & 174.40 & 43.30 \\
\hline 2 & 46.98 & 83.10 & 43.47 \\
\hline 3 & 26.37 & 42.27 & 37.62 \\
\hline 5 & 83.81 & 135.45 & 38.12 \\
\hline 6 & 56.45 & 104.92 & 46.20 \\
\hline 7 & 112.64 & 206.20 & 45.37 \\
\hline 8 & 73.88 & 134.22 & 44.96 \\
\hline 9 & 23.97 & 56.74 & 57.75 \\
\hline 10 & 130.24 & 231.33 & 43.70 \\
\hline Average Value & - & - & 44.50 \\
\hline
\end{tabular}

Cutting- impeller control of pumps. The pump doesn't compliance with similarity law when impeller cutting. So, similarity theory cannot be used to convert the parameters of the pump impeller cutting back and forth. Under the circumstances of a small amount of cutting, the approximate calculation of the formula given in the literature [10]:

$$
\begin{aligned}
& \frac{\mathrm{Q}^{\prime}}{\mathrm{Q}}=\frac{\mathrm{D}^{\prime}}{\mathrm{D}} \\
& \frac{\mathrm{H}^{\prime}}{\mathrm{H}}=\left(\frac{\mathrm{D}^{\prime}}{\mathrm{D}}\right)^{2} \\
& \frac{\mathrm{N}^{\prime}}{\mathrm{N}}=\left(\frac{\mathrm{D}^{\prime}}{\mathrm{D}}\right)^{3}
\end{aligned}
$$

Where $\mathrm{D}$ is the outer diameter before cutting the impeller; $\mathrm{D}^{\prime}$ is the outer diameter after cutting the impeller; Q, N, H are flow, head and shaft power of pump before cutting impeller; Q', N', H' are flow, head and shaft power of pump after cutting impeller.

It can be obtained by the formula:

$$
\frac{\mathrm{N}^{\prime}}{\mathrm{N}}=\left(\frac{\mathrm{Q}^{\prime}}{\mathrm{Q}}\right)^{3}
$$

It is same to the relationship between the shaft power and flow when the variable-speed control. Therefore, it has a good energy saving effect when achieve the system design flow by using pump impeller cutting.

\section{Conclusions}

The measured flow rate of pump is 19.3 percent higher than that of design flow rate on average, and the measured efficiency of pump is 58.9 percent on average.

Large water pump flow rate and low efficiency is the actual energy consumption which is significantly higher than the ideal condition. The actual energy consumption is 131.4 percent higher than that of ideal condition on average in 10 projects. That is to say. 
Higher flow rate and lower efficiency of pump result from oversized selection, the main problem of which is oversized pump head. The rate head is 87.6 percent higher than required head on average in 10 projects. The reason of oversized head is that pressure loss of the system is not calculate accurately, or take too much surplus amount into account when the head is determined.

Adopting the throttle to achieve design flow caused pump energy consumption fell by $8.8 \%$ on average. But variable speed regulation make pump energy consumption fell by $44.5 \%$ on average. It also has a good energy saving effect when using cutting- impeller control.

\section{References}

[1] L.B. Liu, L. Fu, Y. Jiang. Electrical power consumption analysis of circulating pumps in central heating systems for residential quarters. HV\&AC 38(1); 2008, 123-126.

[2] Z.H. Dong. Some problems about resistance calculation and circulating pump selection in air conditioning water systems. HV\&AC 36(9); 2009, 45-47.

[3] Y.Q. Lu. Practical design manual of heating and air conditioning. China Building Industry Press. 2008:1181.

[4] G.C. Gong. Fluid transmission and distribution network. Machinery Industry Press. 2005:372.

[5] Y.Q. Lu, Z.L. Ma. Heating Ventilation \& Air Conditioning. China Building Industry Press. 2007:339.

[6] B.N. Zhou. Central air conditioning equipment selection manual. China Building Industry Press. 1999:647.

[7] P.L. Chen, X.F. Yue. Handbook of air conditioning and refrigeration technology. Tongji University Press. 1990:342.

[8] X.Z. Fu, Y.R. Wang, Y. wang. Fluid transmission and distribution network. Machinery Industry Press. 2001:231.

[9] Y.Z. Fu, H.D. Zhou, Z.W. Liu. Application of water pump proportionality law to heating and air conditioning systems. HV\&AC 40(2); 2010, 39-42, 72.

[10] N.X. Chen, Y.L. Wu. Centrifugal Pump. Machinery Industry Press. 2003:82. 